\title{
再帰ニューラルネットを用いた車両運動性の代理モデリング
}

牧野 晃平 ${ }^{* 1}$, 三輪 誠*2, 新谷 浩平 ${ }^{* 3}$, 阿部 充治*4, 佐々木 裕 ${ }^{* 2}$

\section{Surrogate modeling of vehicle dynamics using Recurrent Neural Networks}

\author{
Kohei MAKINO*1, Makoto MIWA*2, \\ Kohei SHINTANI ${ }^{* 3}$, Atsuji $\mathrm{ABE}^{* 4}$ and Yutaka SASAKI ${ }^{* 2}$ \\ ${ }^{* 1,{ }^{*} 2}$ Toyota Technological Institute \\ 2-12-1 Hisakata, Tempaku-ku, Nagoya-shi, Aichi 468-8511, Japan \\ *3,*4 Toyota Motor Corporation \\ 1 Toyota-cho, Toyota-shi, Aichi 471-8571, Japan
}

Received: 19 May 2020; Revised: 5 August 2020; Accepted: 17 September 2020

\begin{abstract}
Computer Aided Engineering (CAE) is indispensable for vehicle design to reduce the development cost; however, its computation time is a heavy burden when tuning design parameters. In this respect, several studies have been carried out for replacing CAE with machine learning-based surrogate models. In this paper, we propose a novel neural sequence network-based surrogate model for CAE using Recurrent Neural Networks (RNNs), which are neural networks that treat sequences such as temporal sequences. Our target task is the NCAP Fishhook test to evaluate vehicle dynamics of the rollover propensity. We propose a machine learning model with a sequential model to calculate the response of the NCAP Fishhook test from vehicle parameters such as tire and suspension characteristics. Our model reduced the error in approximately $10 \%$ for the NCAP Fishhook test dataset, which is generated with CAE, compared to that of the baseline neural network model with multi-layer perceptrons (MLPs). Furthermore, to improve performance and stability, our model has the following task-specific characteristics: (1) the skip connection, (2) the hybrid loss, and (3) the scheduled sampling. We confirmed that the skip connection reduced errors in the additional ablation study. Our experiments showed that the sequential model is effective as a surrogate model for CAE, and we also find that there is still room for the improvement regarding the dataset and the model because the accuracy is not saturated with the current dataset.
\end{abstract}

Keywords : Deep learning, Neural Network, Recurrent Neural Network, NCAP Fishhook test, CAE, Skip connection, Scheduled sampling

\section{1. 緒言}

車両開発では，CAE（Computer Aided Engineering）解析を活用することで，実機によらない検討が可能であり， 開発を効率化することができる。また，開発の初期段階で用いれば，複数の車両性能目標を満足する緒元・特性 の許容集合を求めることができ，目標值の割り付けに利用できる．このような検討では，実験計画に基づく計算 や，最適化手法による反復計算など，複数回の計算が求められる場合がある。しかしながら，非定常現象に対す る CAE 解析など計算コストが大きい場合や，設計変数が多い場合の最適化問題などでは，限られた開発期間の 中で十分な反復計算を実施するのは困難である.

近年では CAE の代理モデル（Surrogate Model）として機械学習を用いるアプローチが注目されている. 特に開

No.20-00177 [DOI:10.1299/transjsme.20-00177], J-STAGE Advance Publication date : 30 September, 2020

本論文は，第29回設計工学・システム部門講演会 講演論文集(2019), No.2209の掲載内容に基づいた論文である.

${ }^{* 1}$ 学生員, 豊田工業大学（广468-8511 愛知県名古屋市天白区久方 2-12-1）

*2 豊田工業大学

*3 正員, トヨタ自動車（株）（干471-8571 愛知県豊田市卜ヨタ町 1）

*4 トヨタ自動車 (株)

E-mail of corresponding author: yutaka.sasaki@toyota-ti.ac.jp 
Makino, Miwa, Shintani, Abe and Sasaki, Transactions of the JSME (in Japanese), Vol.86, No.891 (2020)

発の初期には定性的な傾向を捉える必要があり，概算を目的とした代理モデルが利用できる．計算量が多い流体 力学の分野では, Ladickýらのランダムフォレストを用いた手法 (Ladický et al., 2015) や, Yang らのニューラル ネットワークを用いた手法（Yang et al., 2016）のような研究がある. これらの研究では流体のシミュレーション を軽量化し，計算コストを低減するために，CAEの計算結果の再現を機械学習モデルによって行った.

このような一般的な機械学習モデルでは，事前に機械学習モデルを学習するためのデータを用意しなければな らない，試行回数が膨大になるような設計変数が多い問題に対しては，学習の進行に合わせてモデルの訓練に必 要なデータを判定する能動学習（Konyushkova et al., 2017）によって，一部の少ない試行のデータのみをもとに学 習した代理モデルを利用することで，全体としてのコストを低減する試みも行われている.

既存の機械学習を用いた CAE の代理モデルは，系列全体を考慮するようなモデルを用いておらず，車両運動 性能の CAE 解析のように一続きの系列を考慮する必要がある対象への適用が困難である. 車両運動性能におけ る評価指標では，機構解析により得られた時刻歴挙動を用いて定義される場合があるため，緒元に対して系列デ ータを予測する代理モデルが必要である.

本研究の目的は，代理モデルとして系列を考慮した深層学習モデルを用いた，車両の設計変数を変化させて行 う車両性能解析の精度を向上させることである. ベースラインとして, 単純なニューラルネットワーク構造の一 種である多層パーセプトロン（Multi Layer Perceptron; MLP）を用いて，ある設計変数の組において走行試験を行 った際の結果を, 系列予測を省いて計算するモデル化をしたが, 誤差が大きく車両開発に使用することは困難で あったそそこで本研究では，RNN（Recurrent Neural Network）（Rumelhart et al., 1986）を用いて系列予測を行い, 実際のCAE を模倣して精度を向上することを目的とする。

本研究の貢献は以下の点である.

・機械学習を用いた車両走行シミュレーションに対しての系列モデル RNN の導入

系列の特徵を捉えられるニューラルネットワーク構造である RNN をモデルに導入し, ベースラインと比較 することで, 車両走行シミュレーションに対する系列モデルの有効性を検証した. 系列モデルを導入すること で，MLPのみを用いたベースラインモデルと比べて最終的な試験の結果の予測精度が改善された.

・深層学習モデルに関する手法の有効性を確認

層を飛ばした結合を増やすことで性能を向上させるスキップコネクション（He et al., 2016）の有無や, 二ュ ーラルネットワークの最適化時のスケジューリング手法であるスケジュールドサンプリング (Bengio et al., 2015）の有無など, 複数種類のモデルについて調查を行い, 有効なモデルを検証した.

本論文の構成は 5 章からなり，2 章では本研究の関連研究，3 章では提案するモデル，4 章ではモデルの性能の 調査および考察， 5 章で結論を述べる.

\section{2. 関連研究}

\section{$2 \cdot 1$ ニューラルネットワーク}

ニューラルネットワーク（Rosenblatt, 1958）は人間の脳の神経細胞を模した数理モデルである. ベースライン のモデルとして用いる MLP は, 入力を $\boldsymbol{x}, l$ 層目の重み行列を $\boldsymbol{W}^{(l)}, l$ 層目に対寸る非線形関数を $f^{(l)}(\boldsymbol{x})$, 出力を $\hat{\boldsymbol{y}}$, 全層数をL層とすると,

$$
\hat{y}=f^{(L)}\left(\ldots f^{(l)}\left(\boldsymbol{W}^{(l)} f^{(l-1)}\left(\ldots f^{(1)}\left(\boldsymbol{W}^{(1)} \boldsymbol{x}\right) \ldots\right)\right) \ldots\right)
$$

と表せる.このようにニューラルネットワークでは出力が非線形関数の組み合わせで表現され，データに対して 重み行列Wを最適化すると多様な関数を近似可能である.

RNN（Rumelhart et al., 1986）はニューラルネットワークの構造の一種で, 系列を扱うことに長けたモデルであ る. RNN は時刻歴の状態を記憶するための内部状態 $\boldsymbol{h}$ を保持しており, 内部状態に今まで入力された系列の情報 を保持して系列の特徵を捉えることができる.しかし，RNNには，計算グラフが一続きとなり勾配消失や勾配爆 
発が起こりや寸い点と, 内部状態を次のステップに渡寸際に近接のステップのみを入力として次のステップを出 力するため，長期的な記憶ができず，長い系列を扱うことが困難という点の二点の問題点がある.

この問題を解決するために提案されたのが Long Short-Term Memory（LSTM） (Hochreiter and Schmidhuber, 1997) である．LSTM は勾配を伝えるために，全系列にわたって共通した記憶が存在する．共通した記憶にはステップ 毎に忘却の操作と，入力に対して新たに記憶する情報の取捨選択寸る機構がある. これらの機構によって LSTM ではシミュレーションのようなタイムステップが小さい場合に生じるような長い系列を扱うことができる. 本研 究ではこのLSTM を用いて系列を考慮したモデルを構築する.

\section{$2 \cdot 2$ 勾配法}

一般的にニューラルネットワークの最適化は, 非線形最適化問題であることから勾配法によって行う. 勾配法 では，重みは以下の更新式により更新される.

$$
\boldsymbol{w}_{t+1} \leftarrow \boldsymbol{w}_{t}+\eta \Delta \boldsymbol{w}_{t}
$$

ここで, $\eta>0$ は学習量を調節する学習率, $\boldsymbol{w}_{t}$ は学習ステップtにおけるモデルの重み, $\Delta \boldsymbol{w}_{t}$ は重みの勾配である.

その中でも，データに対する最適化を繰り返して最適解を得る手法である確率的勾配法 (Stochastic Gradient Descent; SGD）を用いることが多い（Bottou, 2010）。学習を効率的に進めるためには，学習率の調整を適切に行う 必要がある, 通常の SGD では, 学習率の調整は人手で行わなければならない. そこで提案されたのが Adam

(Adaptive moment estimation)（Kingma and Ba, 2014）である，Adam は勾配に対する慣性を考えることで効率的 に学習を進めることができ, 学習率も人手で制御する必要はない.

勾配法は最適化の対象となるデータによって学習の特性が変化する. 全てのデータに対して同時に最適化する バッチ学習, データ一つずつに対して順番に最適化するオンライン学習, そして定めたミニバッチサイズ分に分 割したデータに対して最適化するミニバッチ学習の三種類がある. バッチ学習は学習が進みやすいが局所解に陥 りや寸いという問題が，オンライン学習はデータのノイズに対して脆弱という問題がある. これらを合わせた方 法がミニバッチ学習で, 適切なミニバッチサイズで学習することで両者の問題を解決し, 効果的に学習を進めら れる.

\section{$2 \cdot 3$ NCAP Fishhook 試験}

New Car Assessment Program Fishhook（NCAP Fishhook）試験（NHTSA, 2013）は，National Highway Traffic Safety Administration（NHTSA）が定めた，車両の動的な転倒傾向の調查のための試験である。この試験の概要を図 1 に示した.この試験は二つの手順からなり, 第一段階で後の手順で用いるステアリング入力角 $\delta(t)$ を定め, 第二 段階でそのステアリング入力角 $\delta(t)$ に合わせて釣り針型に走行する. 本試験は規定車速における車両転覆挙動の 発生有無を評価する事を本来の目的としているが，走行時の車両状態量として表 1 に示寸項目等を測定し，車両 諸元との関連性を把握しておくことが，車両開発を進める上で有用である.

Table 1 Evaluation items for the NCAP Fishhook test

\begin{tabular}{c} 
Evaluation Item \\
\hline Maximum of role angle \\
Minimum of lateral acceleration \\
Minimum of vertical load at tire contact point (Right and Left) \\
\hline
\end{tabular}




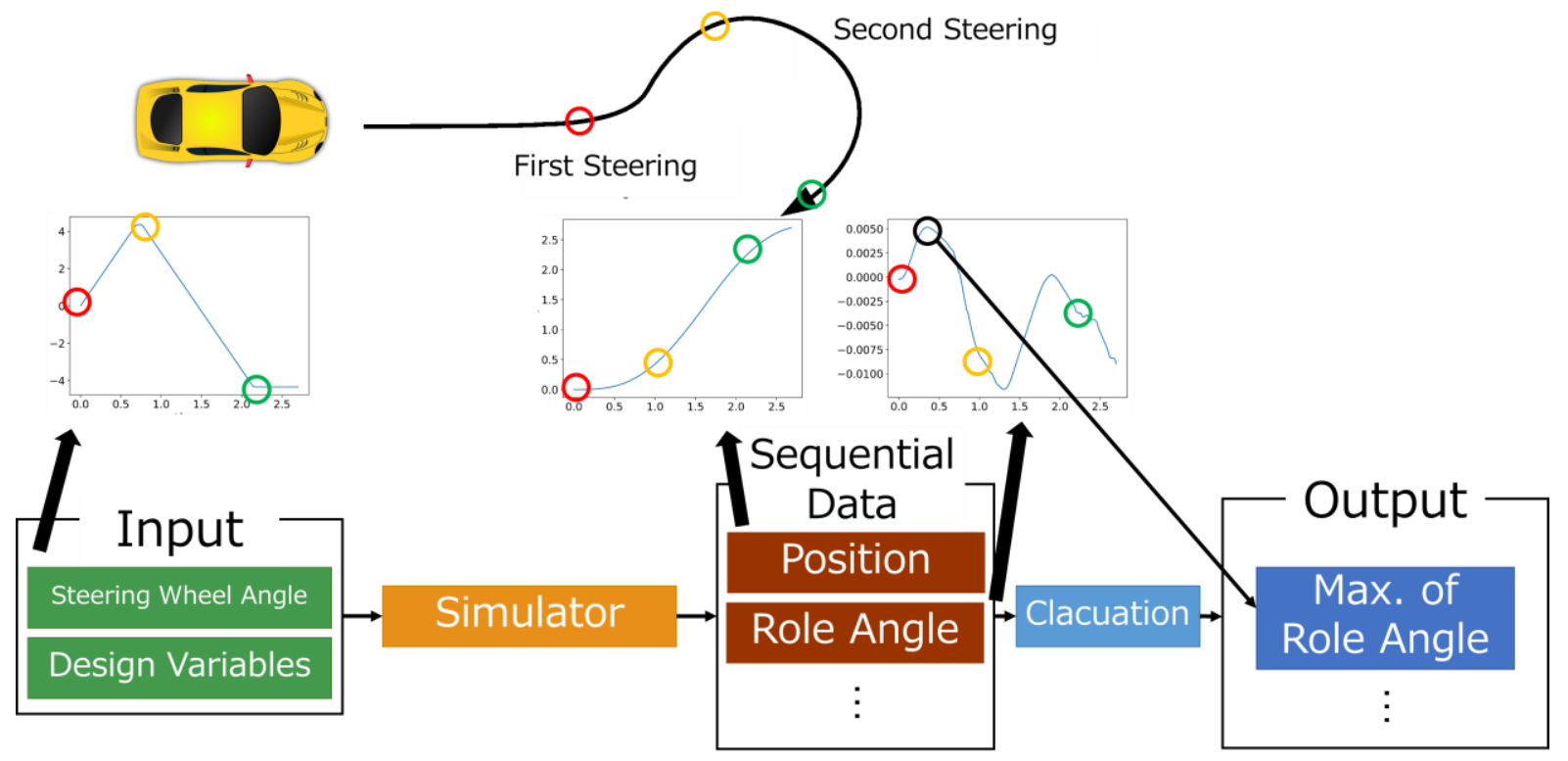

Fig. 1 Overview of the NCAP Fishhook test.

\section{3. 提案手法}

本研究では, 機械学習による車両走行シミュレーションに対して系列モデル LSTM を導入する. 提案モデルで は精度向上のために CAE を模して，実際のCAE 解析で行う計算をモデル化して精度向上を図る.

$3 \cdot 1$ 節ではタスクの設定について，3・2 節では提案モデルとして系列を考慮するモデルについて述べる. $3 \cdot 3$ 節では提案モデルを最適化するために用いる損失関数について, $3 \cdot 4$ 節ではモデルの性能を向上させるためのス キップコネクションについて，3・5 節では安定した学習のためのスケジュールドサンプリングについて述べる.

\section{Input Part Simulation Part Intermediate Calculation Part}

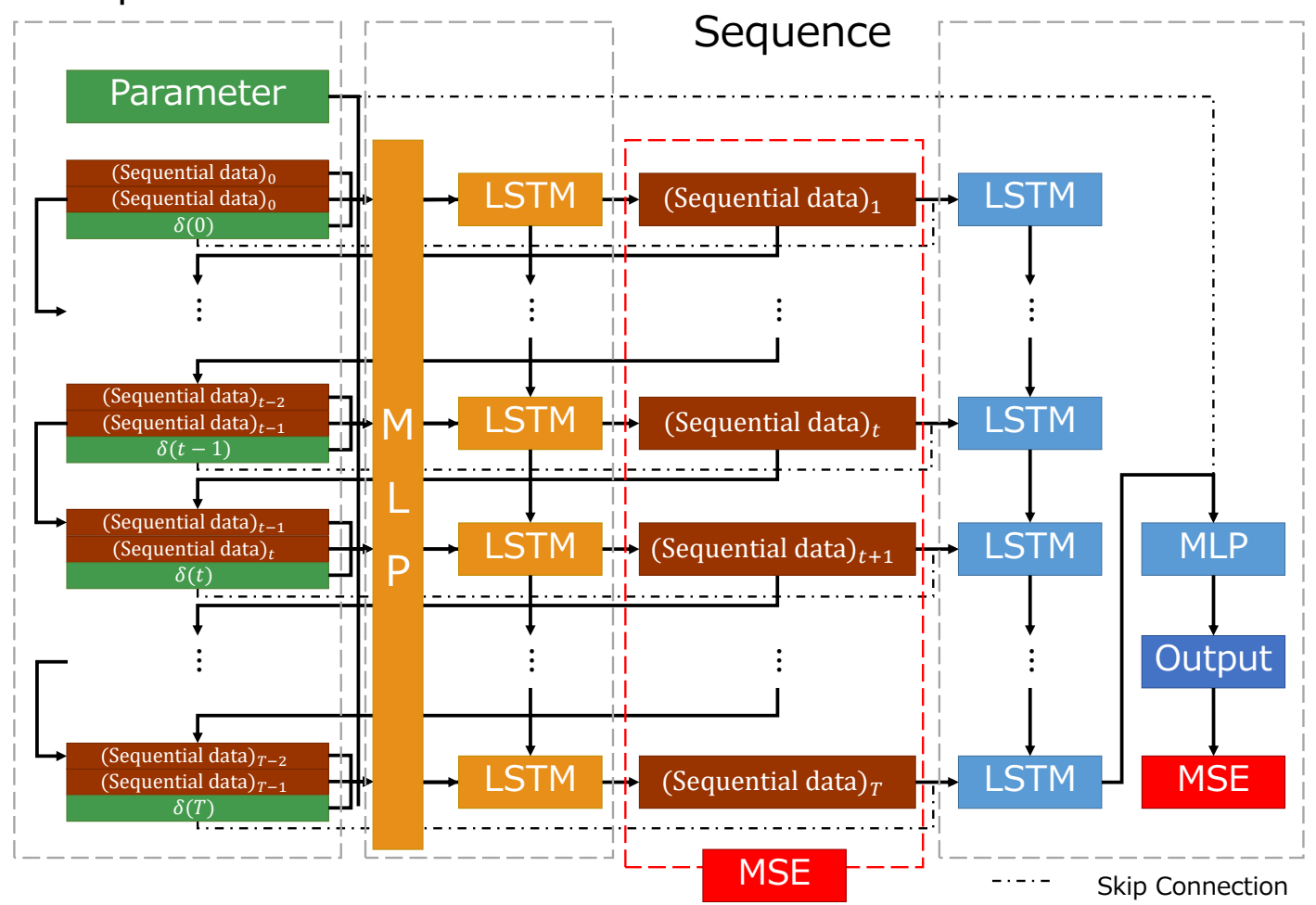

Fig. 2 Overview of our model. 


\section{$3 \cdot 1$ タスク設定}

本研究では車両走行シミュレーションの中でも，2・3 節で述べた NCAP Fishhook 試験を対象とする. 図 1 は試 験の第二段階である釣り針型に走行する部分の構成を表している．本研究のモデルは，この試験に対してタイヤ 特性やサスペンション特性などのパラメタの最適化を行うことを目的に, 計算コストを削減するための代理モデ ルを構築する．ここでは，準静的な動作の第一段階に比べて計算量が多い，第二段階である釣り針状の走行部を 対象にモデル化する. 入力を設計変数とステアリング入力角 $\delta(t)$ とし, 出力は表 1 の NCAP Fishhook 試験におけ る車両を特徴づける応答となる. 設計変数はタイヤの特性や車両の重量特性, サスペンションの剛性など, 転倒 傾向を特徵づけるものを選択した．学習時には中間で計算された系列を学習データとして用いる.

\section{$3 \cdot 2$ 系列を考慮したモデル}

図 2 の提案モデルは大きく分けて, 入力部とシミュレータを模しているシミュレータ部, 得られた系列データ から最終的な応答を抽出するための演算部の三部に分けられる. まず入力部でデータを受け取り，シミュレータ 部で中間の系列を計算する．そしてその系列から応答を演算部で抽出するという流れで計算する.

\section{$3 \cdot 2 \cdot 1$ 入力部}

各タイムステップにおける入力は設計変数とそのステップにおけるステアリング入力角と直前の 2 ステップの 中間計算をした系列である. 全体で系列長がTのタイムステップのうち, あるステップを $t$ とし $t$ tにおける入力 である $\boldsymbol{x}_{t}$ は設計変数とステアリング入力角を結合したもので， $N$ 次元の設計変数を $\boldsymbol{p}=\left[p_{1}, p_{2}, \cdots, p_{N}\right]$, ステアリ ング入力角を $\boldsymbol{\delta}=\left[\delta_{1}, \delta_{2}, \cdots, \delta_{t}, \cdots, \delta_{T}\right]$ とすると， $\boldsymbol{x}_{t}$ は以下のように表せる.

$$
\boldsymbol{x}_{t}=\left[\delta_{t}, p_{1}, p_{2}, \cdots, p_{N}\right]
$$

ただし, 車両の速度が安定して第一操舵が開始される直前を $t=0$ と定める. 設計変数は一つの系列の中では時刻 によって変化しないため同一の值であり，それぞれのステップtでは，ステップごとに変化するステアリング入力 角 $\delta_{t}$ と，すべてのステップで同一值の設計変数 $\boldsymbol{p}$ を力する.

\section{$3 \cdot 2 \cdot 2$ シミュレータ部}

シミュレータ部では, 入力に対してシミュレータを模して順次計算し，系列を計算する．このシミュレータ部 は結合層と LSTM で構成する. 結合層は入力を特徵付ける特徵量を得るための層で, 各ステップで入力から特徵 量を抽出する．LSTM はシミュレータの順次計算を模倣するための系列モデルである．結合層のネットワークを $\operatorname{MLP}(\boldsymbol{x}), \operatorname{LSTM}$ をLTM $(\boldsymbol{x})$ と表し, シミュレータ部ではそれぞれMLP $\mathrm{P}_{\text {sim }}(\boldsymbol{x}), \operatorname{LSTM}_{\text {sim }}(\boldsymbol{x})$ と表すと, 系列の予測 值となるこのシミュレータ部のステップtにおける出力 $\hat{\mathbf{z}}_{t}$ は,

$$
\hat{\mathbf{z}}_{t}=\operatorname{LSTM}_{s i m}\left(\operatorname{MLP}_{s i m}\left(\left[\boldsymbol{x}_{t-1}, \hat{\mathbf{z}}_{t-1}, \hat{\mathbf{z}}_{t-2}\right]\right)\right)
$$

となる. 順次計算のために直前 2 ステップの中間の系列を入力しているのは，モデルが微分項の計算を可能に するためである. シミュレーションでは, 微分方程式で物理的な事象を表すことが多く, 効果的だと考えられる.

しかし， $\hat{\mathbf{z}}_{1}$ の計算時を考えると，初期值 $\hat{\mathbf{z}}_{0}=z_{0}$ は車両を固定して実験を行うことで与えられるが， $\hat{\mathbf{z}}_{-1}$ は存在 しないため, 計算できない. そこで, シミュレーションの初期は緩やかな動作である, と仮定して初期ステップ では式（5）とすることで問題を解決する.

$$
\widehat{\mathbf{z}}_{1}=\operatorname{LSTM}_{\text {sim }}\left(\operatorname{MLP}_{\text {sim }}\left(\left[\boldsymbol{x}_{0}, \hat{\mathbf{z}}_{0}, \hat{\mathbf{z}}_{0}\right]\right)\right)
$$

\section{$3 \cdot 2 \cdot 3$ 演算部}

この提案モデルではシミュレータ部で得られた中間計算した系列に対して応答を end-to-end に抽出する. 計算 した系列を演算部の LSTMに入力し，その系列から応答を得るために必要な特徵量を抽出する. その特徵量から 
結合層で応答を計算する. 応答の推定値となる演算部の出力を $\widehat{y}$, 演算部の LSTM と結合層をそれぞれLSTM cal $(\boldsymbol{x})$, $\operatorname{MLP}_{c a l}(\boldsymbol{x})$ とすると，

$$
\widehat{\boldsymbol{y}}=\operatorname{MLP}_{c a l}\left(\operatorname{LSTM}_{c a l}(\hat{\mathbf{z}})\right)
$$

と表せる.ここで， $\hat{\mathbf{z}}=\left[\hat{\mathbf{z}}_{1}, \hat{\mathbf{z}}_{2}, \cdots, \hat{\mathbf{z}}_{T}\right]$ であ.

\section{$3 \cdot 3$ ハイブリッド損失}

損失関数は中間の系列と応答, 両者に対して同時にモデルを最適化できるようにハイブリッドな損失を用いる. このモデルでは中間の系列と応答の両者を計算している. これは複数の目的関数に対してモデルの最適化を行う マルチタスク学習（Li et al., 2017）（Xu et al., 2020）の問題と考えられ，どちらも最適化できるように，用いる損 失関数は, 式（7）のようにハイブリッドに中間の系列と応答の損失を用いる. 損失 $L$ は以のように表せる.

$$
L=\alpha \operatorname{MSE}(\mathbf{z}, \widehat{\mathbf{z}})+\beta \operatorname{MSE}(\boldsymbol{y}, \widehat{\boldsymbol{y}})
$$

ここで，yは応答の真値，zは中間の系列の真値， $\alpha$ と $\beta$ はハイパーパラメタで定数，MSE（Mean Square Error，二 乗誤差）は以下のように表せる.

$$
\operatorname{MSE}(\boldsymbol{x}, \boldsymbol{y})=\frac{1}{N} \sum_{i=1}^{N}\left(x_{i}-y_{i}\right)^{2}
$$

\section{$3 \cdot 4$ スキップコネクション}

スキップコネクション（He et al., 2016）を加え，層を通すことで久落してしまった情報を付加し直すことで精 度向上を図る（Li et al., 2018）（Huang et al., 2017）。提案モデルは 3・2 節で述べたとおり，中間計算の系列を計算 するシミュレータ部と応答を抽出する演算部の二段階で構成されている. そのため, シミュレータ部は系列デー タを得るために最適化され, 演算部に到達するときには入力した情報が久落してしまうと考えられる. そこで, 設計変数とステアリング入力角を演算部に渡寸ためにスキップコネクションを用いる.

ステアリング入力角は演算部のLSTMに, 設計変数は抽出された特徵量から応答を計算する結合層に結合する. 図 2 の一点鎖線部がスキップコネクションである．このときの演算部の式（6）を書き直すと以下のようになる.

$$
\widehat{\boldsymbol{y}}=\operatorname{MLP}_{c a l}\left(\left[\operatorname{LSTM}_{c a l}([\hat{\mathbf{z}}, \boldsymbol{s}]) ; \boldsymbol{p}\right]\right)
$$

\section{$3 \cdot 5$ スケジュールドサンプリング}

本提案モデルではシミュレータの順次計算を模倣するために， 1 ステップ前の予測值を入力として扱う．この ことから学習初期には誤差を含む予測から次の予測值を予測する必要があり, 学習が不安定になると考えられる.

そこで，スケジュールドサンプリング（Bengio et al., 2015）を用いて，徐々に解を最適化する. スケジュール ドサンプリングでは，学習初期は予測值を入力とするのではなく，式（10）のように真值 $\mathbf{z}_{t}$ を入力として扱うこ とで, ステップ毎には誤差が少ない解にモデルを最適化する.

$$
\hat{\mathbf{z}}_{t}=\operatorname{LSTM}_{\text {sim }}\left(\operatorname{MLP}_{\text {sim }}\left(\left[\boldsymbol{x}_{t-1}, \mathbf{z}_{t-1}, \mathbf{z}_{t-2}\right]\right)\right)
$$

その後学習が進むにつれ, 徐々に予測值を入力するようにし, 全系列に渡って誤差が少ないように最適化する. $\widehat{\mathbf{z}}_{1}$ の計算時は真值における 2 ステップ前の $\mathbf{z}_{-1}$ が存在しないが，式（5）と同様に，動作の開始はなめらかである と仮定して，入力を $\left[\boldsymbol{x}_{t-1}, \boldsymbol{z}_{0}, \mathbf{z}_{0}\right]$ のようにする. 


\section{4. モデルの評価および考察}

\section{4 - 1 実験設定}

提案手法の実験のプログラムは，プログラム言語 Python version 3.6.6を用いて実装した. 用いた深層学習環境 は PyTorch version 1.0 (Paszke et al., 2017）である. 実験に用いた計算機の主な環境を表 2 に示す.

Table 2 Computation environment.

\begin{tabular}{cc}
\hline CPU & Intel(R) Core(TM) i7-6700K CPU @ 4.00GHz \\
GPU & GeForce GTX TITAN X (Pascal) \\
Memory & 64GB \\
\hline
\end{tabular}

データセットは図 1 のように，入力と中間計算される系列と出力となる応答からなる，データは，入力である 19 次元の設計変数と系列データのステアリング入力角, 31 次元の系列データ, そして出力となる中間の時系列デ ータから表 1 のように抽出した 5 次元の応答を一つとし, 表 3 の構成で作成した. データセットは, CAEを用い て，NCAP Fishhook 試験を模擬する時系列シミュレーションを実験計画に基づいて繰返し行うことで取得した. また：シミュレーションには汎用車両運動解析ソルバを用いた。すべてのデータは前処理として平均 0 , 分散 1 に正規化した.

Table 3 Statistics of the dataset.

\begin{tabular}{cccc}
\hline Train & Development & Test & Total \\
\hline 600 & 76 & 76 & 752 \\
\hline
\end{tabular}

ネットワークの構成は表 4 に示したように, シミュレータ部では入力から結合層によって特徵量となり, LSTM に入力, 中間の系列の次元に落とすために結合層を入れて中間の系列が得られる. 中間の系列を得るための結合 層では，正則化としてドロップアウト（Srivastava et al., 2014）を加えた. 演算部は中間の系列を入力として，結 合層で次元を増やし，LSTM で可変長の系列を特徴量に落としこみ，ドロップアウトの正則化を加えた結合層で 最終的な出力である応答を得た. 活性化関数となる非線形関数には出力層を除くすべての層でReLU $(x)=$ $\max (0, x)$, 出力層では恒等関数 $f(x)=x$ を用いた.

Table 4 The network structure in our model.

\begin{tabular}{cccc}
\hline & ID & Layer & Dimension \\
\hline \hline \multirow{2}{*}{ Simulation } & 1 & Fully connected layer + ReLU & 512 \\
part & 2 & LSTM + ReLU & 512 \\
& 3 & Fully connected layer + Dropout $\quad(0.1)$ & 512 \\
\hline \multirow{2}{*}{ Calculation } & 4 & Output (intermediate Sequence) & 31 \\
part & 5 & Fully connected layer + ReLU & 512 \\
& 6 & LSTM + ReLU & 512 \\
\hline
\end{tabular}

評価指標は応答の平均平方誤差（Root Mean Square Error; RMSE）を用いた。 RMSE は，

$$
\operatorname{RMSE}(\boldsymbol{y}, \widehat{\boldsymbol{y}})=\sqrt{\frac{1}{D} \sum_{i=1}^{D}\left(y_{i}-\hat{y}_{i}\right)^{2}}
$$

と表せる.ただし，Dはデータの数である．それぞれの応答における誤差 $e_{i}(i=1,2, \cdots, 5)$ は, 


$$
e_{i}=\operatorname{RMSE}\left(y_{i}, \widehat{y}_{l}\right)
$$

となる. モデルの性能を示す指標として，応答のそれぞれの RMSEである $e_{i}$ の平均を定義する.

$$
\bar{e}=\frac{1}{5} \sum_{i=1}^{5} e_{i}
$$

この值が小さければ，モデルの推定精度が高いことを示し，検証したモデルが有効であることが確認できる.

実験手順は，構築したモデルの重みをPyTorch の乱数で初期化し，学習した後にテストを行う。最適化手法は Adam, 学習はバッチサイズ 16 のミニバッチ学習を行った. スコアは, 1 エポック毎に求め, 最も小さい $\bar{e}$ 小っ たときのスコアをその試行に対するスコアとし，10 回異なる初期值で試行した平均でスコアを求めた. $\alpha$ との

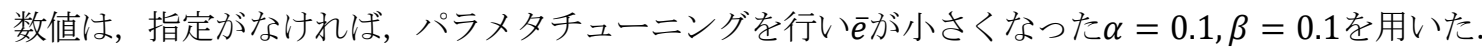

\section{4:2 ベースラインと提案手法の比較}

本提案手法による精度の向上の確認のため, MLPのみのベースラインと提案手法を比較する. ベースラインモ デルは 2 層の MLP で, 中間層の次元をパラメタチューニングしたときに最も良い性能を示したものを用いてい る. 結果は表 5 で，数值が太字になっているものが誤差を少なく，精度がよいものを表している．表 5 に示した 誤差の比較から，すべての応答でベースラインに比べて精度が向上しているとわかる. このことから，提案モデ ルの有効性が確認できた。また，提案手法は応答ごとに誤差の大きさが異なっており，応答全体の誤差にばらつ きがある。これは応答によって推定しやすいものと，しにくいものがある，つまり推定難度が異なると考えられ る.

Table 5 RMSE (MLP vs. ours).

\begin{tabular}{ccccccc}
\hline Model & $e_{1}$ & $e_{2}$ & $e_{3}$ & $e_{4}$ & $e_{5}$ & $\bar{e}$ \\
\hline \hline MLP & 0.4915 & 0.4605 & 0.5555 & 0.3492 & 0.5608 & 0.4835 \\
\hline \multirow{2}{*}{ Ours } & $\mathbf{0 . 0 9 7 3}$ & $\mathbf{0 . 1 1 2}$ & $\mathbf{0 . 4 1 2}$ & $\mathbf{0 . 1 4 2}$ & $\mathbf{0 . 4 9 8}$ & $\mathbf{0 . 2 5 2}$ \\
& $\pm \mathbf{0 . 0 0 2}$ & $\mathbf{\pm 0 . 0 0 2}$ & $\pm \mathbf{0 . 0 0 3}$ & $\pm \mathbf{0 . 0 0 3}$ & $\pm \mathbf{0 . 0 0 3}$ & $\pm \mathbf{0 . 0 0 9}$ \\
\hline
\end{tabular}

この提案した代理モデルを実際に利用する場合を考えたとき，利用可能な部分もあるが，実用的な性能ではな い部分もある．実際に要求されるモデルの性能は，その場合によるが，定性的な傾向を捉えるためにシミュレー ションを行い，設計変数の範囲を絞り込むのが本研究の目的である. 本実験ではデータを平均 0 , 分散 1 に正規 化しているため, 最も誤差が大きい $e_{5}$ の 0.498 は, 絶対的に考えると誤差は大きく, 定性的な評価も難しいこと が予想される. 一方で $e_{1}$ といった誤差が小さい答については定性的な傾向は捉えられていると考えられる.

\section{$4 \cdot 3$ ハイブリッド損失の効果検証}

この節では中間の系列計算の情報を付加することによる効果を確認する. 4 ・2 節ではベースラインと比較して 提案手法の精度が向上したことを確認した. ベースラインと提案手法ではモデルのパラメタ数が異なる. そのパ ラメタ数の寄与による精度の向上か，中間の系列計算を付与したことによる精度の向上かを検証する.ここでは $3 \cdot 4$ 節のハイブリッド損失の式（7）を用いた場合と，式（7）において $\alpha=0$ として応答のみの損失を用いた場 合の比較を行う。この実験によって，シミュレータ部が中間の系列を計算することによる効果を確認できる.

結果は，全体的にハイブリッド損失を用いている場合の方が誤差を削減できた．表 6 の実験の結果からハイブ リッド損失を用いていないものとベースラインと比較すると誤差が減少していることがわかる.よって，パラメ タ数による寄与による性能向上もあるが，ハイブリッド損失を用いることによって中間の系列計算の情報を与え ることで精度が向上したといえる。 
Table 6 Comparison of models with or without the hybrid loss in RMSE.

\begin{tabular}{ccccccc}
\hline Model & $e_{1}$ & $e_{2}$ & $e_{3}$ & $e_{4}$ & $e_{5}$ & $\bar{e}$ \\
\hline \hline \multirow{3}{*}{$\alpha=0$} & 0.105 & 0.119 & 0.429 & 0.147 & 0.511 & 0.26 \\
& \pm 0.002 & \pm 0.003 & \pm 0.006 & \pm 0.004 & \pm 0.006 & \pm 0.01 \\
\hline \multirow{2}{*}{ Ours } & $\mathbf{0 . 0 9 7 3}$ & $\mathbf{0 . 1 1 2}$ & $\mathbf{0 . 4 1 2}$ & $\mathbf{0 . 1 4 2}$ & $\mathbf{0 . 4 9 8}$ & $\mathbf{0 . 2 5 2}$ \\
& $\mathbf{\pm 0 . 0 0 2}$ & $\mathbf{\pm 0 . 0 0 2}$ & $\mathbf{\pm 0 . 0 0 3}$ & $\mathbf{\mathbf { 0 . 0 0 3 }}$ & $\mathbf{\pm 0 . 0 0 3}$ & $\mathbf{\pm 0 . 0 0 9}$ \\
\hline
\end{tabular}

\section{$4 \cdot 4$ スキップコネクションの効果検証}

スキップコネクションをモデルに導入した効果を検証する. 提案手法は $3 \cdot 4$ 節のスキップコネクションを用い ている．これは，シミュレータ部を通すことで最初の入力の情報が落ちている状態で演算部に入力されることを 防ぐためである. 式（9）のようにステアリング角と設計変数をそれぞれ応答部の LSTM と結合層に入力するモ デルと，式（6）のように入力しないモデルで比較する.

結果はスキップコネクションが有るモデルの方が誤差を縮小することができた．その結果が表 7 である.すべ ての推定值において有意に精度が向上している．このことから，スキップコネクションを加えることで，シミュ レータ部を通したことによる情報の欠落を補い，精度を向上することができたといえる.

Table 7 RMSE comparison of models with or without skip connections.

\begin{tabular}{ccccccc}
\hline Model & $e_{1}$ & $e_{2}$ & $e_{3}$ & $e_{4}$ & $e_{5}$ & $\bar{e}$ \\
\hline \hline \multirow{2}{*}{ w/o skip } & 0.1506 & 0.1240 & 0.5977 & 0.2051 & 0.6922 & 0.353 \\
connections & \pm 0.0004 & \pm 0.0002 & \pm 0.0006 & \pm 0.0006 & \pm 0.0007 & \pm 0.002 \\
\hline \multirow{2}{*}{ Ours } & $\mathbf{0 . 0 9 7 3}$ & $\mathbf{0 . 1 1 2}$ & $\mathbf{0 . 4 1 2}$ & $\mathbf{0 . 1 4 2}$ & $\mathbf{0 . 4 9 8}$ & $\mathbf{0 . 2 5 2}$ \\
& $\mathbf{+ 0 . 0 0 2}$ & $\mathbf{\pm 0 . 0 0 2}$ & $\mathbf{\pm 0 . 0 0 3}$ & $\mathbf{\pm 0 . 0 0 3}$ & $\mathbf{\pm 0 . 0 0 3}$ & $\mathbf{\mathbf { 0 . 0 0 9 }}$ \\
\hline
\end{tabular}

\section{$4 \cdot 5$ スケジュールドサンプリングの効果検証}

$3 \cdot 5$ 節のスケジュールドサンプリングの効果を検証する. ここで検証するのはシミュレータ部の入力の一つ前 の状態の入力を，学習時にどのようにスケジューリングするか，つまり推定值と真值をどのように入力するかで ある．以下の三通りのスケジューリング方法を検証する.

（1）常に真値を入力

常にシミュレータの入力に真值を用いる．訓練時は式（10), テスト時には式（4）に従って計算される.

(2) 常に推定值を入力

常にシミュレータ部の入力に推定值を用いる. 式（4）にしたがって訓練とテストが行われる.

(3) 徐々に真值から推定值へと入力を変化

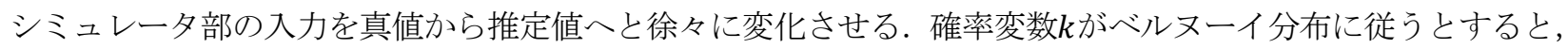
確率関数は式（14）で与えられる.

$$
f(k ; q)=q^{k}(1-q)^{1-k}
$$

入力の変化のさせ方は, 以下のように表す.

$$
\mathbf{z}_{t}=\left\{\begin{array}{l}
\operatorname{LSTM}_{\text {sim }}\left(\operatorname{MLP}_{\text {sim }}\left(\left[\boldsymbol{x}_{t-1} \mathbf{z}_{t-1}\right]\right)\right), \quad \text { if } k=1 \\
\operatorname{LSTM}_{\text {sim }}\left(\operatorname{MLP}_{\text {sim }}\left(\left(\left[\boldsymbol{x}_{t-1} \hat{\mathbf{z}}_{t-1}\right]\right)\right),\right. \text { otherwise }
\end{array}\right.
$$


ここでは入力を徐々に真值から推定值へ変化させるために以下のようにする. 学習時のエポック数を三分割し,

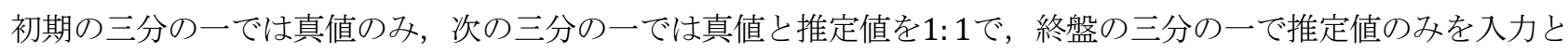
して用いるようにqの值を変化させる.

$$
q=\left\{\begin{array}{cl}
1, & \text { if } \frac{\text { \#epoch }}{\text { \#NUM_EPOCHS }}<\frac{1}{3} \\
0.5, & \text { if } \frac{1}{3} \leq \frac{\text { \#epoch }}{\text { \#NUM_EPOCHS }}<\frac{2}{3} \\
0, & \text { if } \frac{2}{3} \leq \frac{\text { \#epoch }}{\text { \#NUM_EPOCHS }}
\end{array}\right.
$$

ただし, \#epochは現在のエポック数, \#NUM_EPOCHSは全体のエポック数とする. エポック数とは, 学習時にデ

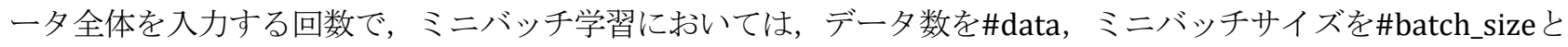
したとき，\#NUM_EPOCHS × \#data/\#batch_size回の重みの更新が行われる.

結果は表 8 で, 徐々に入力を変化させる（3）のスケジューリング方法が最も誤差が小さくなった.（1）の誤差 が大きくなったのは，訓練時とテスト時にギャップがあり，（1）は真值のみを入力して訓練して，テスト時には 推定值を入力としているためであると考えられる.（2）は最終的な誤差が大きくなっている．これは推定值のみ で学習していて, 訓練時とテスト時のギャップはないが, 学習初期にはノイズを多く含んだ推定值を入力してい るため, 学習が不安定になっていると考えられる.

Table 8 RMSE comparison of scheduled sampling methods.

\begin{tabular}{ccccccc}
\hline Model & $e_{1}$ & $e_{2}$ & $e_{3}$ & $e_{4}$ & $e_{5}$ & $\bar{e}$ \\
\hline \hline \multirow{2}{*}{$(1)$} & $\mathbf{0 . 0 9 6 7}$ & 0.116 & 0.420 & 0.140 & 0.508 & 0.26 \\
& $\pm \mathbf{0 . 0 0 2}$ & \pm 0.002 & \pm 0.005 & \pm 0.002 & \pm 0.006 & \pm 0.01 \\
\hline \multirow{2}{*}{$(2)$} & 0.101 & $\mathbf{0 . 1 1 0}$ & 0.425 & $\mathbf{0 . 1 3 5}$ & 0.516 & 0.26 \\
& \pm 0.004 & $\pm \mathbf{0 . 0 0 3}$ & \pm 0.004 & $\pm \mathbf{0 . 0 0 4}$ & \pm 0.006 & \pm 0.01 \\
\hline \multirow{2}{*}{$(3)$} & 0.0973 & 0.112 & $\mathbf{0 . 4 1 2}$ & 0.142 & $\mathbf{0 . 4 9 8}$ & $\mathbf{0 . 2 5 2}$ \\
& \pm 0.002 & \pm 0.002 & $\mathbf{\pm 0 . 0 0 3}$ & \pm 0.003 & $\pm \mathbf{0 . 0 0 3}$ & $\pm \mathbf{0 . 0 0 9}$ \\
\hline
\end{tabular}

\section{$4 \cdot 6$ 計算時間の比較}

提案モデルによる計算コストの改善を確認するため, 実際の CAE を用いた場合と代理モデルの計算時間の比 較を行う. 提案モデルの訓練に対して要した時間は, 実験に用いた 10 のモデルの平均で $170 \mathrm{sec} / \mathrm{epoch}$ 要した. 学習は 100 epoch 行ったので, 訓練全体では約 $4.7 \mathrm{~h}$ であった. さらにテストとして推論を行った場合に要する時 間は，76 のテストデータに対して $0.23 \mathrm{sec}$ の計算時間であった. 一方で CAEを用いた場合，1つのケースの計算 に要する時間は約 $5.5 \mathrm{~min}$ であった.

開発初期における検討では，緒元・特性の範囲を絞り込む検討を要するが，この問題を多設計変数に適用する 場合，その設計变数の数に対して指数関数的に計算コストが増大寸る．提案モデルを用いた検討に要する時間は （1）訓練データ・開発データの作成のために CAEの計算に要する時間，（2）モデルを訓練する時間，（3）最適 化問題に要する時間であるのに対し, CAE を用いた検討に要する時間は最適化に必要な試行をすべて CAE で計 算する時間である. CAE と代理モデルのそれぞれの場合に全体で要する時間を $T_{s u r}[\mathrm{~h}], T_{C A E}[\mathrm{~h}]$, 最適化に必要な 試行回数を $x$ とすると, 本実験で用いた 600 の訓練データを作成して用いる場合, その差は概算で以下のように 表せる.

$$
T_{C A E}-T_{\text {sur }}=\left(\frac{5.5}{60} x\right)-\left(4.7+\frac{5.5}{60} \times 676+\frac{0.23}{60^{2}} \div 76 \times x\right) \approx 0.092 x-67
$$


Makino, Miwa, Shintani, Abe and Sasaki, Transactions of the JSME (in Japanese), Vol.86, No.891 (2020)

この概算から，最適化に約 730 回以上の試行が必要な場合に代理モデルの計算コストが CAE の計算コストを下 回るといえる. 設計変数の数に対して試行回数は指数関数的に増大するため, 多設計变数の最適化の場合は代理 モデルの方が有効である. 例えば，本実験のように設計変数の数が 19 で，それぞれがn種類の状態をとり，グリ

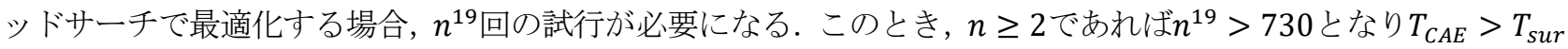
となるため，代理モデルの方が計算コストの面で有利である．ただし，代理モデルを現実で利用するためには， モデルのパラメタチューニングやデータの前処理のような作業に時間が必要になる．この点から，試行回数が膨 大にならない場合には CAE を直接利用して最適化を行う方が，計算コストが小さくなる場合もあると考えられ る.

\section{$4 \cdot 7$ データ数に対するモデルの性能}

図 3 のデータ数と推定誤差の平均eの関係から，すべてのデータを使っているが，まだ精度が飽和していない 状態にあることがわかる．このことから，データ数を増やすと更なる性能の向上が見込める．しかしながら，デ 一タ数を増やすのは, CAE を用いたシミュレーションによって, データ 1 件につき $5.5 \mathrm{~min}$ の時間を要するため, コストが高い. データ数の拡張は開発コストの増加につながるため, 仮想的にデータを増やすデータ拡張のよう な手法や，同数のデータでも能動学習を用いて計画的に生成したデータにする，などの方法が必要である.

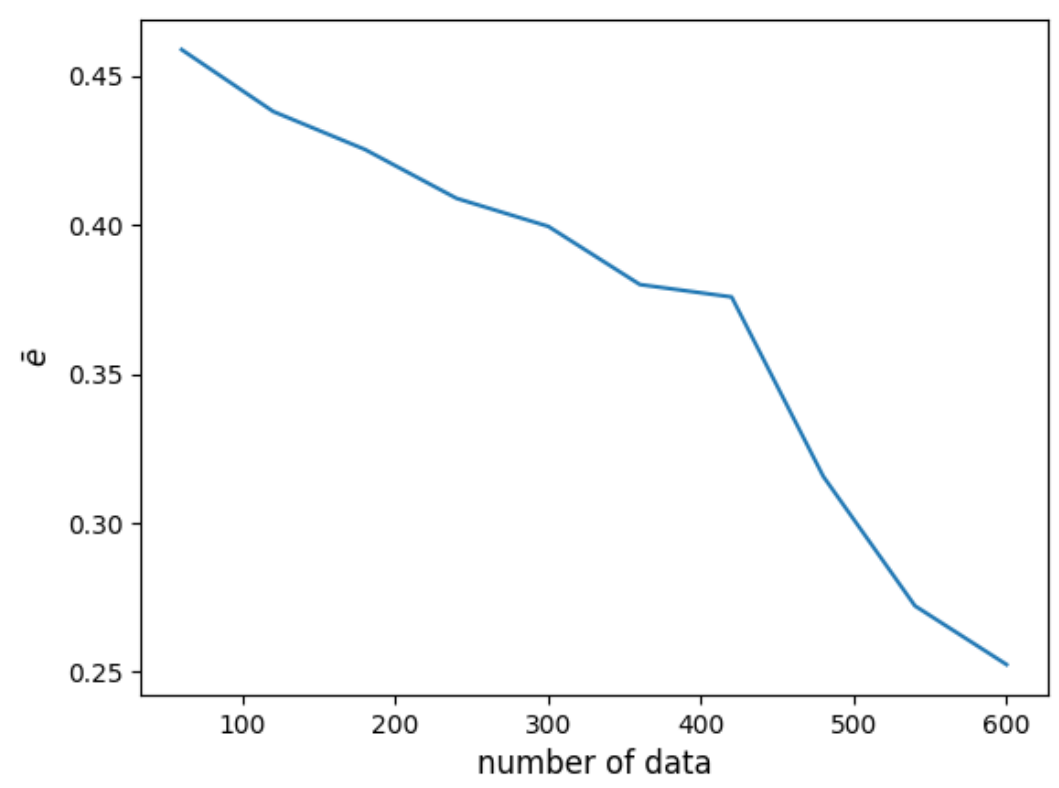

Fig. 3 Error rate vs. the number of training instances.

\section{5. 結 言}

本研究では CAE の代替モデルとして, 設計変数から直接的に応答を求めるベースラインモデルに対して精度 向上を図るために, 系列モデルを導入し, 系列学習を行った. その結果ベースラインモデルよりも精度の高い代 理モデルを構築できた. シミュレータの系列計算を系列モデル LSTM によってモデル化し，そのパラメタから end-to-end に応答を抽出するモデルを提案した。 さらに，ハイブリッド損失・スキップコネクション・スケジュ ールドサンプリングによって精度向上を図った，実験では本提案手法がベースラインと比べ，推定する応答パラ メタの 5 次元のうち, すべてに対しての誤差が縮小し, 全体として代理モデルの性能が向上したと確認できた. また，ハイブリッド損失・スキップコネクション・スケジュールドサンプリングを用いない実験を行い，誤差が 縮小寸ることを確認した.

本論文の提案モデルでは，チューニング箇所が多く，ドロップアウトを加えるなどのチューニングする余地が 残されている. ネットワークの全ての部分で層を単層にして行ったため層の深さや，その他のモデル構造に関す 
るチューニングも今後の課題である。また，データ数に対するモデルの性能が飽和していないため，データ数を 増やす必要がある.ただし，データを単純に増強するのは開発コストが増加してしまうため，データ拡張による 仮想的なデータの水増しや，同数のデータ数でより高い効果を得るために能動学習を取り入れてデータをモデル の学習に対して計画的に生成することも検討する.

\section{References}

Bengio, S., Vinyals, O., Jaitly, N. and Shazeer, N., Scheduled sampling for sequence prediction with recurrent neural networks, In Advances in Neural Information Processing Systems (2015), pp. 1171-1179.

Bottou, L., Large-scale machine learning with stochastic gradient descent, In Proceedings of COMPSTAT'2010 (2010), pp. 177-186, Physica-Verlag HD.

He, K., Zhang, X., Ren, S. and Sun, J., Deep residual learning for image recognition, In Proceedings of the IEEE conference on computer vision and pattern recognition (2016), pp. 770-778.

Hochreiter, S. and Schmidhuber, J., Long short-term memory, Neural computation, Vol. 9, No. 8 (1997), pp. 1735-1780.

Huang, G., Liu, Z., Van Der Maaten, L. and Weinberger, K. Q., Densely connected convolutional networks, In Proceedings of the IEEE conference on computer vision and pattern recognition (2017), pp. 4700-4708.

Kingma, D. P. and Ba, J., Adam: A method for stochastic optimization, In Proceedings of International Conference on Learning Representations (2014).

Konyushkova, K., Raphael, S. and Fua, P., Learning active learning from data, Advances in Neural Information Processing Systems 30 (2017), pp. 4225-4235.

Ladický, L. U., Jeong, S., Solenthaler, B., Pollefeys, M. and Gross, M., Data-driven fluid simulations using regression forests, ACM Transactions on Graphics (TOG), Vol. 34, No. 6 (2015), pp. 1-9.

Li, C., Yan, J., Wei, F., Dong, W., Liu, Q. and Zha, H., Self-paced multi-task learning, In Proceedings of Thirty-First AAAI Conference on Artificial Intelligence (2017).

Li, H., Xu, Z., Taylor, G., Studer, C. and Goldstein, T., Visualizing the loss landscape of neural nets, In Advances in Neural Information Processing Systems (2018), pp. 6389-6399.

National Highway Traffic Safety Administration (NHTSA), Laboratory test procedure for dynamic rollover: the fishhook maneuver test procedure, Washington (DC): US, Department of Transportation (2013).

Paszke, A., Gross, S., Chintala, S., Chanan, G., Yang, E., DeVito, Z., Lin, Z., Desmaison, A., Antiga, L. and Lerer, A., Automatic differentiation in PyTorch, NIPS 2017 Autodiff Workshop (2017).

Rosenblatt, F., The perceptron: a probabilistic model for information storage and organization in the brain, Psychological review, Vol. 65, No. 6 (1958), p. 386.

Rumelhart, D. E., Hinton, G. E. and Williams, R. J., Learning representations by back-propagating errors, Nature, Vol. 323, No. 6088 (1986), pp. 533-536.

Srivastava, N., Hinton, G., Krizhevsky, A., Sutskever, I. and Salakhutdinov, R., Dropout: a simple way to prevent neural networks from overfitting, The journal of machine learning research, Vol. 15, No. 1 (2014), pp. 1929-1958.

Xu, J., Zhao, L., Zhang, S., Gong, C. and Yang, J., Multi-task learning for object keypoints detection and classification, Pattern Recognition Letters, Vol. 130 (2020), pp.182-188.

Yang, C., Yang, X. and Xiao, X., Data - driven projection method in fluid simulation, Computer Animation and Virtual Worlds, Vol. 27, No. 3, Issue 4 (2016), pp. 415-424. 